\title{
Does the use of targeted agents in advanced gastroesophageal cancer increase complete response? A meta-analysis of 18 randomized controlled trials
}

This article was published in the following Dove Press journal: Cancer Management and Research

\section{Yanyang Pang' \\ Zhen Shen ${ }^{2}$ \\ Jiancheng Sun ${ }^{3}$ \\ Wu Wang ${ }^{4}$}

'Department of Traditional Chinese Medicine, Hainan Medical University, Haikou, Hainan 57I I0I, China;

${ }^{2}$ Division of Liver Disease, Huangshi City Hospital of Traditional Chinese Medicine (Infectious Disease Hospital), Edong Healthcare Group, Huangshi, Hubei 435000, China; ${ }^{3}$ Department of General Surgery, The First Clinical Medical College, Zhejiang Chinese Medical University, Hangzhou, Zhejiang 3 I0053, China; ${ }^{4}$ Laboratory of Tropical Biomedicine and Biotechnology, School of Tropical Medicine and Laboratory Medicine, Hainan Medical University, Haikou, Hainan 57II0I, China
Correspondence: Wu Wang Laboratory of Tropical Biomedicine and Biotechnology, School of Tropical Medicine and Laboratory Medicine, Hainan Medical University, No. 3, Xueyuan Road, Haikou, Hainan 57II0I, China

Tel +8689831350919

Fax +86 898 31350920

Email wangwu2018@yeah.net
Purpose: We aimed to investigate whether the use of targeted agents (TAs) in advanced gastroesophageal cancer (GEC) increased the complete response (CR) and to assess the surrogate endpoints for survival in the targeted treatment of GEC by using a meta-analysis of randomized controlled trials (RCTs).

Methods: Eligible studies were identified using Medline, PubMed, and meeting abstracts. Searches were last updated on April 30, 2018. We calculated the incidence and Peto odds ratio (Peto OR) of CR events in patients assigned to TAs compared with controls. Simple linear regression models were fitted for median overall survival (OS) and each surrogate [median progression-free survival (PFS), CRs, objective response rate (ORR), and disease control rate (DCR), respectively].

Results: A total of 7,892 GEC patients from 18 RCTs were included for analysis. The incidence of CR in GEC patients treated with TAs was 2.0\% (95\% CI, 1.3\%-3.0\%) compared with 1.7\% (95\% CI, 1.0\%-2.7\%) in the control arms. The use of TAs in advanced GEC had a tendency to improve the possibility of archiving CR (Peto OR 1.42; 95\% CI, 0.98-2.04; $P=0.064$ ) compared with controls. Subgroup analysis according to treatment TAs showed that the addition of antiepidermal growth factor receptor (EGFR) agents to chemotherapy in GEC significantly improved the CR rate in comparison with control (Peto OR 1.77; 95\% CI, 1.02-3.09; $P=0.044$ ), but not for other molecular TAs ( $P=0.49$ for angiogenesis inhibitors, $P=0.66$ for mesenchymal-epithelial transition inhibitors). We also found that the addition of TAs to first-line therapy (Peto OR 1.41; 95\% CI, 0.94-2.11; $P=0.098$ ) had a tendency to increase the chance of obtaining a CR, but not for second-line therapy (Peto OR 1.47; 95\% CI, 0.60-3.55; $P=0.40$ ). In addition, correlation analysis indicates that PFS, ORR, and DCR were strongly correlated with OS for GEC patients receiving TAs ( $r=0.85$ for PFS; $r=0.86$ for ORR; $r=0.81$ for DCR). No marked correlation was found between OS and CRs $(r=0.43 ; P=0.18)$.

Conclusion: Although the CR is a rate event in advanced GEC patients, adding the TAs to therapies, especially for anti-EGFR agents, increases the chance of archiving CR in comparison with the controls. PFS, ORR, and DCR are significantly correlated with OS and could be used as surrogate endpoints in patients with GEC who have received TA therapy, but not for CR.

Keywords: gastroesophageal carcinoma, systematic review, novel molecular agents

\section{Introduction}

Gastroesophageal cancer (GEC), which comprises tumors arising from the gastroesophageal junction and the stomach, is the fourth most common malignant disease 
and the second leading cause of cancer mortality worldwide, accounting for $8 \%(989,600$ million $)$ of the total new cancer cases and $10 \%(738,000)$ of the total cancer deaths in 2008. ${ }^{1,2}$ Substantial geographic variation exists in incidence, with the highest incidence rates occurring in Asia, South America, and Eastern Europe. ${ }^{3}$ Until now, the only curative treatment of GEC is surgical resection; however, the majority of GEC (approximately 50\%) are regarded as incurable at initial diagnosis. In addition, most of GEC often relapse even after curative surgery. Doublet or triplet combination chemotherapy containing a platinum-fluoropyrimidine, such as FOLFOX regimen (fluorouracil, leucovorin calcium and oxaliplatin), remains the backbone of treatment for advanced GEC resulting in superior survival outcomes and symptom control and consequently improved quality of life compared with best supportive care. ${ }^{46}$ For gastric cancer overexpressing human epidermal growth factor-2 (HER2), trastuzumab plus chemotherapy is the current standard treatment. ${ }^{7}$ However, the prognosis of GEC patients remains poor, with median survival $<1$ year. ${ }^{8}$ Thus, there is an urgent unmet need to develop novel efficient agents for advanced GEC patients.

During the past decades, the emergence of molecularly targeted agents (TAs), including angiogenesis inhibitors, antiepidermal growth factor receptor (EGFR) agents, or MET inhibitors, has provided another strategy for the treatment of advanced GEC patients. ${ }^{9}{ }^{10}$ Currently, two TAs, including trastuzumab and ramucirumab, have been approved for the treatment of advanced GEC patients. Additionally, a number of novel agents have been extensively investigated in clinical trials. Indeed, multiple meta-analyses have demonstrated that the addition of TAs to chemotherapies in advanced GEC significantly improves overall survival (OS) and progressionfree survival (PFS) when compared with chemotherapy alone. ${ }^{1-14}$ Although these agents have shown greater activity, in terms of PFS or OS, compared with controlled therapies, specifically when compared with placebo, a clinically relevant increase in complete response (CR) was not reported and the role of TAs in increasing the curability of this cancer remains unclear. We thus conducted this meta-analysis of published reports about TA-containing regimens vs placebo or chemotherapy to investigate the incidence rates and relative risk of $\mathrm{CR}$ in advanced gastroesophageal cancer patients.

\section{Methods}

\section{Study design}

We developed a protocol that defined inclusion criteria, search strategy, outcomes of interest, and analysis plan. The reporting of this systematic review adheres to the Preferred
Reporting Items for Systematic Reviews and Meta-Analyses (PRISMA) statements. ${ }^{15}$

\section{Definition of outcomes}

Treatment with TAs was considered as the experimental arms and the other treatments as the standard comparators. CRs were considered as the main outcomes, and the analysis was conducted in order to find a significant difference between the two arms. CRs were defined as disappearance of all target lesions. Any pathological lymph nodes (whether targeted or nontargeted) must have reduction in short axis to $<10 \mathrm{~mm}$ according to Response Evaluation Criteria in Solid Tumors (RECIST) criteria. OS was defined as the period from starting targeted therapy until death or last follow-up. Time to progression/PFS was defined as the period from starting targeted therapy until progression or last follow-up; objective response rate (ORR) was defined as the rate of partial responses and CRs, and disease control rate (DCR) was defined as the rate of partial responses, CR, and stabilization.

\section{Selection of studies}

To identify studies for inclusion in our systematic review and meta-analysis, we did a broad search of four databases, including Embase, PubMed/Medline, the Cochrane Central Register of Controlled Trials, and the Cochrane Database of Systematic Reviews, from the date of inception of every database to April 2018. The search was limited to human studies and randomized controlled trials (RCTs). No language restriction was imposed. If more than one publication was found for the same trial, the most recent was considered for analysis. Abstracts of the American Society of Clinical Oncology (ASCO), the European Society of Medical Oncology Congress since 2002 (ESMO), and the World Gastrointestinal Congress since 2006 were also searched manually.

\section{Data extraction}

Two authors conducted the data extraction independently. It was performed according to the PRISMA statement, ${ }^{16}$ and any types of discrepancies were resolved by consensus. The data extracted for each trial were first author's name, year of publication, number of enrolled patients, dose of TAs, median age, median OS, and median PFS.

\section{Statistical method}

For calculating the incidence, the number of patients with $\mathrm{CR}$ and the number of patients treated in each arm were extracted from the efficacy profile of the selected trials. The proportion of patients with CR and the derived $95 \%$ 
CI were calculated for each study. We also calculated the Peto odds ratio (Peto OR) and the CIs of events in patients assigned to TAs compared with the controlled patients in the same study. To calculate the $95 \%$ CIs, the variance of a logtransformed study-specific RR was derived using the delta method. ${ }^{17}$ Between-study heterogeneity was estimated using the $\chi^{2}$-based $Q$-statistic. ${ }^{18}$ Heterogeneity was considered statistically significant when $P_{\text {heterogeneity }}<0.1$. When substantial heterogeneity was observed, the pooled estimate, calculated based on the random-effects model, was reported using the method described by Dersimonian and Laird, ${ }^{19}$ which considered both within- and between-study variations. We also conducted the prespecified subgroup analyses according to treatment line and treatment regimens. We assessed the potential publication bias by visual inspection of the symmetry of funnel plots and with tests described by Begg and Mazumdar ${ }^{20}$ and Egger et al. ${ }^{21}$ Study quality was assessed by using the Jadad five-item scale that included the randomization, double blinding, and withdrawals; the final score was reported between 0 and $5 .{ }^{22}$ All data were collected using
Microsoft Office Excel 2003; and meta-analysis was performed using version 2 of the Comprehensive Meta-Analysis program (Biostat, Englewood, NJ, USA).

\section{Results}

A total of 550 studies were identified from the database search [PubMed/Medline $(n=320)$, ASCO $(n=120)$, ESMO $(n=50)$, and World Gastrointestinal Congress $(n=60)]$, of which 70 were duplicates and 430 did not meet the inclusion criteria and were therefore exclude. Of these, 50 reports were retrieved for full-text evaluation. A total of 18 trials met the inclusion criteria and were included in this systematic review (Figure 1). ${ }^{23-40}$ The characteristics of patients and studies were listed in Table 1. Overall, a total of 18 studies with 7,892 GEC patients were included. The median number of patients included in each study was 549 patients (range: 60-904 patients). Fourteen studies compared TAs plus chemotherapy with or without placebo, ${ }^{23-25,27,29-36,38,40}$ other four studies compared TAs alone with placebo. ${ }^{26,28,37,39}$ Dosages for each molecule are

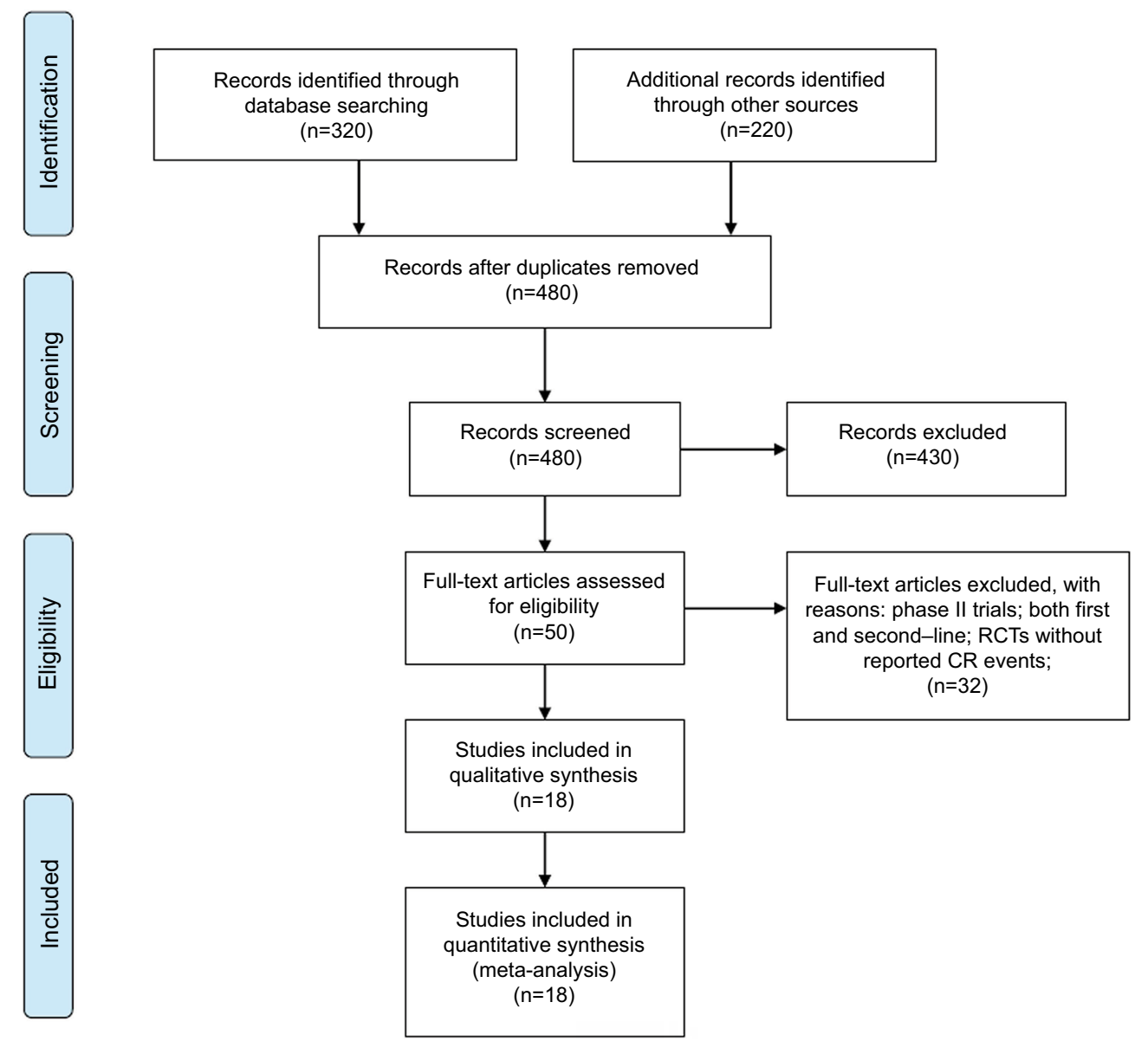

Figure I Selection process for RCTs included in the meta-analysis.

Abbreviations: $\mathrm{CR}$, complete response; RCT, randomized controlled trials. 
Table I Baseline characteristic of included 18 trials for analysis

\begin{tabular}{|c|c|c|c|c|c|c|c|c|c|}
\hline Authors & $\begin{array}{l}\text { Treatment } \\
\text { line }\end{array}$ & Total & Treatment arms & $\begin{array}{l}\text { Median } \\
\text { age (years) }\end{array}$ & $\begin{array}{l}\text { Median } \\
\text { PFS }\end{array}$ & Median OS & CR & $\begin{array}{l}\text { No. for } \\
\text { analysis }\end{array}$ & $\begin{array}{l}\text { Jadad } \\
\text { score }\end{array}$ \\
\hline \multirow[t]{2}{*}{ Shah et al $(2017)^{32}$} & First line & 562 & Onartuzumab $10 \mathrm{mg} / \mathrm{kg}+$ FOLFOX & 60 & 6.8 & II & 4 & 217 & 5 \\
\hline & & & Placebo + FOLFOX & 58 & 6.7 & 11.3 & 4 & 207 & \\
\hline \multirow[t]{2}{*}{$\begin{array}{l}\text { Catenacci et al } \\
(2017)^{33}\end{array}$} & First line & 609 & $\begin{array}{l}\text { Rilotumumab } 15 \mathrm{mg} / \mathrm{kg} \text { + epirubicin } \\
\text { + DDP + capecitabine }\end{array}$ & 61 & 6.05 & 8.8 & 3 & 262 & 5 \\
\hline & & & $\begin{array}{l}\text { Placebo + epirubicin + DDP + } \\
\text { capecitabine }\end{array}$ & 59 & 7.06 & 10.7 & 8 & 267 & \\
\hline \multirow[t]{2}{*}{ Bang et al $(2017)^{34}$} & Second line & 643 & Olaparib 100 mg + PTX & 58 & 3.6 & 8.8 & 4 & 263 & 5 \\
\hline & & & Placebo + PTX & 59 & 5.5 & 6.9 & 1 & 262 & \\
\hline \multirow[t]{2}{*}{ Yoon et al $(2016)^{35}$} & First line & 168 & Ramucirumab 8 mg/kg + FOLFOX & 64.5 & 6.4 & 11.7 & 6 & 84 & 5 \\
\hline & & & Placebo + FOLFOX & 60 & 6.7 & 11.5 & 5 & 84 & \\
\hline \multirow[t]{2}{*}{ Shah et al $(2016)^{36}$} & First line & 123 & Onartuzumab $10 \mathrm{mg} / \mathrm{kg}$ + FOLFOX & 58.5 & 6.77 & 10.61 & 4 & 62 & 5 \\
\hline & & & Placebo + FOLFOX & 57 & 6.97 & 11.27 & 1 & 61 & \\
\hline \multirow{2}{*}{$\begin{array}{l}\text { Pavlakis et al } \\
(2016)^{37}\end{array}$} & Second line & 152 & Regorafenib $160 \mathrm{mg}$ & 63 & 2.6 & 5.8 & 3 & 97 & 5 \\
\hline & & & Placebo & 62 & 0.9 & 4.5 & I & 50 & \\
\hline \multirow{2}{*}{$\begin{array}{l}\text { Moehler et al } \\
(2016)^{38}\end{array}$} & Second line & 90 & Sunitinib + FOLFIRI & 62 & 3.5 & 10.4 & 0 & 45 & 5 \\
\hline & & & Placebo + FOLFIRI & 57 & 3.3 & 8.9 & 5 & 45 & \\
\hline \multirow[t]{2}{*}{ Li et al $(2016)^{39}$} & Second line & 267 & Apatinib & 58 & 2.6 & 6.5 & 4 & 176 & 5 \\
\hline & & & Placebo & 58 & 1.8 & 4.7 & 0 & 91 & \\
\hline \multirow[t]{2}{*}{ Hecht et al $(2016)^{40}$} & First line & 545 & Lapatinib I,250 mg + CapeOx & 61 & 6 & 12.2 & 6 & 249 & 5 \\
\hline & & & Placebo + CapeOx & 59 & 5.4 & 10.5 & 4 & 238 & \\
\hline \multirow[t]{2}{*}{ Du et al $(2015)^{31}$} & First line & 60 & $\begin{array}{l}\text { Nimotuzumab } 200 \mathrm{mg} / \mathrm{m}^{2}+ \\
\text { chemotherapy }\end{array}$ & 58 & 4.8 & 10.2 & 1 & 31 & 3 \\
\hline & & & Chemotherapy & 53 & 7.2 & 14.3 & 0 & 31 & \\
\hline \multirow{2}{*}{$\begin{array}{l}\text { Fuchs et al } \\
(2014)^{28}\end{array}$} & Second line & 335 & Ramucirumab $8 \mathrm{mg} / \mathrm{kg}$ & 60 & NR & 5.2 & 1 & 238 & 5 \\
\hline & & & Placebo & 60 & NR & 3.8 & 0 & 117 & \\
\hline \multirow{2}{*}{$\begin{array}{l}\text { Wilke H. et al } \\
(2014)^{30}\end{array}$} & First line & 655 & Ramucirumab $8 \mathrm{mg} / \mathrm{kg}+\mathrm{PTX}$ & 61 & 4.4 & 9.6 & 2 & 330 & 5 \\
\hline & & & Placebo + PTX & 61 & 2.9 & 7.4 & I & 335 & \\
\hline \multirow[t]{2}{*}{ Shen et al $(2015)^{29}$} & Second line & 202 & $\begin{array}{l}\text { Bevacizumab } 2.5 \mathrm{mg} / \mathrm{kg} / \mathrm{wk}+ \\
\text { capecitabine + DDP }\end{array}$ & 54.2 & 6 & 11.4 & 1 & 86 & 5 \\
\hline & & & Placebo + capecitabine + DDP & 55.5 & 6.3 & 10.5 & 0 & 81 & \\
\hline \multirow{2}{*}{$\begin{array}{l}\text { Waddell et al } \\
(2013)^{27}\end{array}$} & First line & 553 & Panitumumab $9 \mathrm{mg} / \mathrm{kg}+\mathrm{EOC}$ & 63 & 7.4 & 11.3 & 8 & 254 & 3 \\
\hline & & & EOC & 62 & 6 & 8.8 & 5 & 238 & \\
\hline \multirow[t]{2}{*}{ Ohtsu et al $(2013)^{26}$} & Second line & 656 & Everolimus $10 \mathrm{mg} / \mathrm{d}$ & 62 & 1.7 & 5.4 & 1 & 379 & 5 \\
\hline & & & Placebo & 62 & $\mathrm{I} .4$ & 4.3 & 0 & 191 & \\
\hline \multirow{3}{*}{$\begin{array}{l}\text { Lordick et al } \\
(2013)^{25}\end{array}$} & First line & 904 & Cetuximab $400 \mathrm{mg} / \mathrm{m}^{2}$ followed by & 60 & 4.4 & 9.4 & 2 & 455 & 3 \\
\hline & & & $250 \mathrm{mg} / \mathrm{m}^{2}+$ capecitabine + DDP & & & & & & \\
\hline & & & Capecitabine + DDP & 59 & 5.6 & 10.7 & 2 & 449 & \\
\hline \multirow[t]{2}{*}{ Ohtsu et al $(20 \mathrm{II})^{24}$} & First line & 774 & $\begin{array}{l}\text { Bevacizumab } 2.5 \mathrm{mg} / \mathrm{kg} / \mathrm{wk}+ \\
\text { capecitabine + DDP }\end{array}$ & 58 & 6.7 & 12.1 & 5 & 387 & 5 \\
\hline & & & Placebo + capecitabine + DDP & 59 & 5.3 & 10.1 & 3 & 387 & \\
\hline \multirow[t]{2}{*}{ Bang et al $(2010)^{23}$} & First line & 594 & $\begin{array}{l}\text { Trastuzumab } 8 \mathrm{mg} / \mathrm{kg} \text { followed by } 6 \\
\mathrm{mg} / \mathrm{kg}+\text { chemotherapy }\end{array}$ & 59.4 & 6.7 & 13.8 & 16 & 294 & 3 \\
\hline & & & Chemotherapy & 58.5 & 5.5 & 11.1 & 7 & 290 & \\
\hline
\end{tabular}

Abbreviations: CapeOx, cisplatin plus oxaliplatin; CR, complete response; DDP, cisplatin; EOC, epirubicin plus oxaliplatin plus capecitabine; FOLFIRI, 5Fu/Lv plus irinotecan; FOLFOX, 5Fu/Lv plus oxaliplatin; NR, not reported; OS, overall survival; PFS, progression-free survival; PTX, paclitaxel.

reported in Table 1. Among the included trials, the role of trastuzumab and lapatinib was investigated in HER2positive GEC patients, and onartuzumab and rilotumumab were assessed in advanced MET-positive GEC patients, while other TAs were investigated in unselected GEC patients. The quality of each included study was roughly assessed according to Jadad scale, and 14 trials had Jadad score of 5, and four trials had Jadad scores of 3. 


\section{Incidence of CR}

CRs were reported in 71 of 3,909 patients in the experimental arm, with an incidence of $2.0 \%$ (95\% CI, 1.3\%-3.0\%; Figure 2) compared with 47 of 3,424 patients treated in the control arm, with an incidence of $1.7 \%$ (95\% CI, $1.0 \%-2.7 \%)$.

\section{Peto OR of CR}

A total of 7,892 patients from 18 RCTs were included for analysis. The Peto OR of CR was 1.42 (95\% CI, 0.98-2.04;
$P=0.064)$ in patients treated with TAs compared with the controls, according to the fixed effects model $(P=0.89$; $\left.I^{2}=0 \%\right)$. We then performed the subgroup analysis according to treatment line and showed that the addition of TAs to first-line therapy had a tendency to increase the chance of achieving CRs (Peto OR 1.41; 95\% CI, 0.94-2.11; $P=0.06$; Figure 3), but not for second-line therapy (Peto OR 1.47; 95\% CI, $0.60-3.55 ; P=0.40)$. Of note, the occasional wide variation in the CIs might indicate that using TAs as a secondline therapy might also substantially increase the Peto OR of
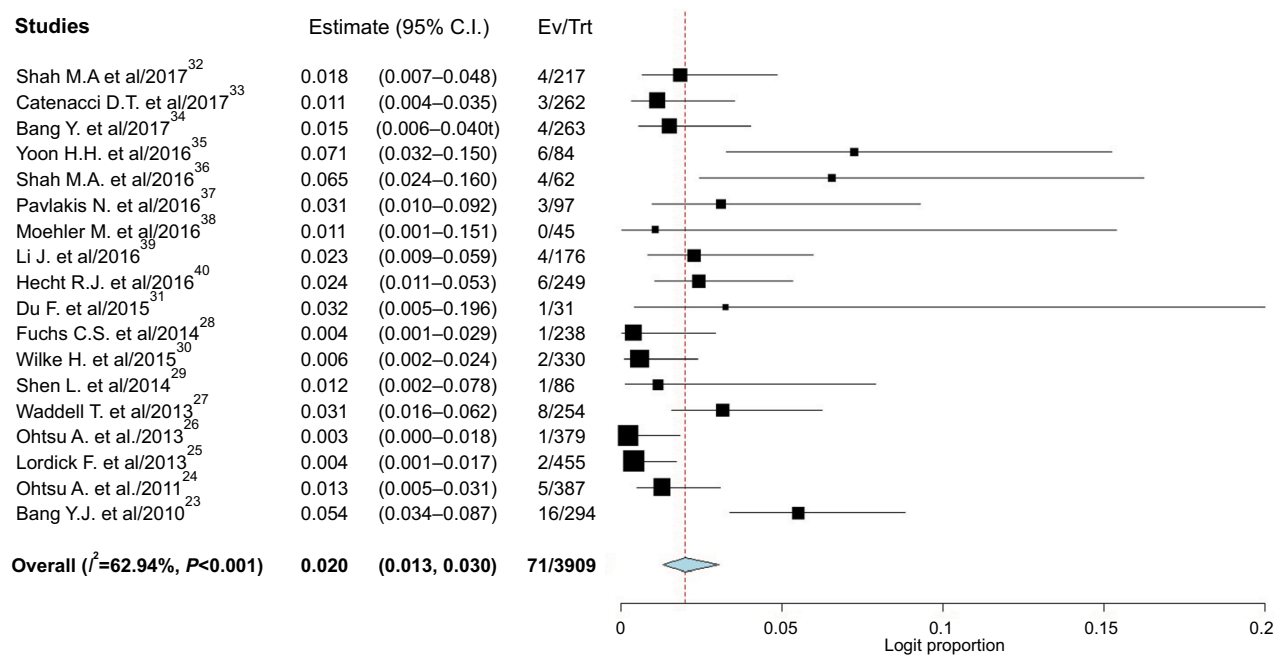

Figure 2 Pooled incidence of complete response associated with targeted agents.

\begin{tabular}{|c|c|c|c|c|c|c|}
\hline \multirow{2}{*}{$\frac{\text { Group by }}{\text { line }}$} & \multirow[t]{2}{*}{ Study name } & \multicolumn{5}{|c|}{ Statistics for each study } \\
\hline & & $\begin{array}{c}\text { Peto } \\
\text { odds ratic }\end{array}$ & $\begin{array}{l}\text { Lower } \\
\text { o limit }\end{array}$ & $\begin{array}{l}\text { Upper } \\
\text { limit }\end{array}$ & Z-Value & $P$-Value \\
\hline first-line & Shah M.A. et al/2017 32 & 0.953 & 0.236 & 3.857 & -0.067 & 0.946 \\
\hline first-line & Catenacci D.T. et al/2017 & $7^{33} 0.404$ & 0.122 & 1.331 & -1.490 & 0.136 \\
\hline first-line & Yoon H.H. et al/2016 & 1.213 & 0.359 & 4.106 & 0.311 & 0.756 \\
\hline first-line & Shah M.A. et $a l / 2016^{36}$ & 3.401 & 0.572 & 20.217 & 1.346 & 0.178 \\
\hline first-line & Hecht R.J. et al/2016 ${ }^{40}$ & 1.436 & 0.411 & 5.019 & 0.566 & 0.571 \\
\hline first-line & Du F. et al/2015 & 7.389 & 0.147 & 372.385 & 1.000 & 0.317 \\
\hline first-line & Wilke H. et al/ $2015^{30}$ & 1.981 & 0.205 & 19.115 & 0.591 & 0.554 \\
\hline first-line & Waddell T. et al/2013 27 & 1.502 & 0.499 & 4.518 & 0.724 & 0.469 \\
\hline first-line & Lordick F. et al/2013 25 & 0.987 & 0.139 & 7.028 & -0.013 & 0.989 \\
\hline first-line & Ohtsu A. et al./2011 & 1.656 & 0.412 & 6.664 & 0.710 & 0.477 \\
\hline first-line & Bang Y.J. et al/2010 23 & 2.224 & 0.966 & 5.116 & 1.880 & 0.060 \\
\hline first-line & & 1.406 & 0.939 & 2.105 & 1.654 & 0.098 \\
\hline second-li & Bang Y. et al/ $/ 2017^{34}$ & 3.338 & 0.574 & 19.398 & 1.343 & 0.179 \\
\hline second-line & Pavlakis N. et al/2016 37 & 1.507 & 0.186 & 12.184 & 0.384 & 0.701 \\
\hline second-lin & Moehler M. et al/2016 38 & 0.123 & 0.020 & 0.741 & -2.288 & 0.022 \\
\hline second-line & Li J. et al/2016 39 & 4.638 & 0.580 & 37.101 & 1.446 & 0.148 \\
\hline second-line & Fuchs C.S. et al/2014 & 4.444 & 0.069 & 287.494 & 0.701 & 0.483 \\
\hline second-line & Shen L. et al/2014 ${ }^{2}$ & 6.972 & 0.138 & 351.970 & 0.970 & 0.332 \\
\hline second-lin & Ohtsu A. et al./2013 & 4.499 & 0.071 & 286.070 & 0.710 & 0.478 \\
\hline secor & & 1.465 & 0.604 & 3.552 & 0.845 & 0.398 \\
\hline Overall & & 1.416 & 0.981 & 2.044 & 1.855 & 0.064 \\
\hline
\end{tabular}


CRs, but there was lack of statistical power to demonstrate a significant difference. In addition, subgroup analysis to specific TAs showed that the addition of anti-EGFR agents to chemotherapy in GEC significantly improved the CR rate in comparison with control (Peto OR 1.77; 95\% CI, 1.02-3.09; $P=0.044)$, but not for other molecular TAs ( $P=0.49$ for angiogenesis inhibitors, $P=0.66$ for MET inhibitors, Figure 4).

\section{Publication bias}

No evidence of publication bias was detected for the Peto OR of CRs in this study by funnel plots (Figure S1), Begg's test $(P=0.36)$, and Egger's test $(P=0.37)$.

\section{Correlation between OS and PFS/ORR/ DCR/CR}

Data from 18 cohorts were available for correlation analysis between OS and PFS. There was a strong correlation between median OS and median PFS $(r=0.85)$, and this correlation was statistically significant $(P<0.001$; Figure 5$)$. Data from 18 cohorts were available for correlation analysis between median OS and ORR/DCR/CR. A significant correlation between median OS and ORR/DCR was also observed ( $r=0.86$ and $r=0.81$, respectively), and this correlation was statistically significant $(P<0.0001$ and $P<0.0001$; Figure S2).
No marked correlation was found between median OS and CRs ( $r=0.43, P=0.18$; Figure S2).

\section{Discussion}

Despite the major advances in chemotherapy during the past decades, only a small number of GEC patients receiving chemotherapy can achieve CR. Although several case reports have been published, overall incidence and likelihood of achieving a $\mathrm{CR}$ in GEC receiving TAs has not been systematically determined. ${ }^{41-43}$ In addition, obtaining a CR is independently associated with improved survival not only for GEC but also for other solid and hematologic malignancies. ${ }^{44-46}$ As a result, it is of particular importance to determine whether the use of TAs would increase the CR events in GEC patients.

Our meta-analysis included a total of 7,892 patients from 18 RCTs and demonstrated that the overall incidence of CR in patients treated with TAs is $2.0 \%(95 \% \mathrm{CI}, 1.3 \%-3.0 \%)$ compared with $1.7 \%(95 \% \mathrm{CI}, 1.0 \%-2.7 \%)$ in the control arms. In addition, we also found that adding TAs has a tendency to improve the possibility of archiving CR (Peto OR 1.42; 95\% CI, 0.98-2.04; $P=0.064$ ) compared with controls. Subgroup analysis showed that the addition of TAs to first-line therapy has a tendency to increase the chance of achieving CRs (Peto

\begin{tabular}{|c|c|c|c|c|c|c|}
\hline \multirow{2}{*}{$\frac{\text { Group by }}{\text { regimens }}$} & \multirow[t]{2}{*}{$\underline{\text { Study name }}$} & \multicolumn{5}{|c|}{ Statistics for each study } \\
\hline & & $\begin{array}{c}\text { Peto } \\
\text { odds rati }\end{array}$ & $\begin{array}{l}\text { Lower } \\
\text { limit }\end{array}$ & $\begin{array}{l}\text { Upper } \\
\text { limit }\end{array}$ & Z-Value & $P$-Value \\
\hline Als & Yoon H.H. et al/2016 ${ }^{35}$ & 1.213 & 0.359 & 4.106 & 0.311 & 0.756 \\
\hline Als & Pavlakis N. et al/2016 & 1.507 & 0.186 & 12.184 & 0.384 & 0.701 \\
\hline Als & Moehler M. et al/2016 & 0.123 & 0.020 & 0.741 & -2.288 & 0.022 \\
\hline Als & $\mathrm{Li}$ J. et al/2016 & 4.635 & 0.580 & 37.101 & 1.446 & 0.148 \\
\hline Als & Fuchs C.S. et al/2014 ${ }^{28}$ & 4.444 & 0.0692 & 87.494 & 0.701 & 0.483 \\
\hline Als & Wilke H. et al/2015 30 & 1.981 & 0.205 & 19.155 & 0.591 & 0.554 \\
\hline Als & Shen L. et al/2014 29 & 6.972 & 0.1383 & 351.970 & 0.970 & 0.332 \\
\hline Als & Ohtsu A. et al./2011 24 & 1.656 & 0.412 & 6.664 & 0.710 & 0.477 \\
\hline Als & & 1.264 & 0.652 & 2.452 & 0.693 & 0.488 \\
\hline EGFR agents & Hecht R.J. et al/2016 40 & 1.436 & 0.411 & 5.019 & 0.566 & 0.571 \\
\hline EGFR agents & Du F. et al/2015 31 & 7.389 & 0.1473 & 372.385 & 1.000 & 0.317 \\
\hline EGFR agents & Waddell T. et al $/ 2013^{27}$ & 1.502 & 0.499 & 4.518 & 0.724 & 0.469 \\
\hline EGFR agents & Lordick F. et al/2013 ${ }^{25}$ & 0.987 & 0.139 & 7.028 & -0.013 & 0.989 \\
\hline EGFR agents & Bang Y.J. et al/2010 23 & 2.224 & 0.966 & 5.116 & 1.880 & 0.060 \\
\hline EGFR agents & & 1.771 & 1.015 & 3.089 & 2.012 & 0.044 \\
\hline MET inhibitors & Shah M.A. et al/201732 & 0.953 & 0.236 & 3.857 & -0.067 & 0.946 \\
\hline MET inhibitors & Catenacci D.T. et al $/ 2017^{33}$ & ${ }^{33} 0.404$ & 0.122 & 1.331 & -1.490 & 0.136 \\
\hline MET inhibitors & Shah M.A. et al/2016 & 3.401 & 0.572 & 20.217 & 1.346 & 0.178 \\
\hline MET inhibitors & & 0.834 & 0.372 & 1.874 & -0.439 & 0.661 \\
\hline others & Bang Y. et al/2017 34 & 3.338 & 0.574 & 19.398 & 1.343 & 0.179 \\
\hline others & Ohtsu A. et al./201326 & 4.499 & 0.0712 & 86.070 & 0.710 & 0.478 \\
\hline others & & 3.493 & 0.691 & 17.657 & 1.513 & 0.130 \\
\hline Overall & & 1.416 & 0.981 & 2.044 & 1.855 & 0.064 \\
\hline
\end{tabular}

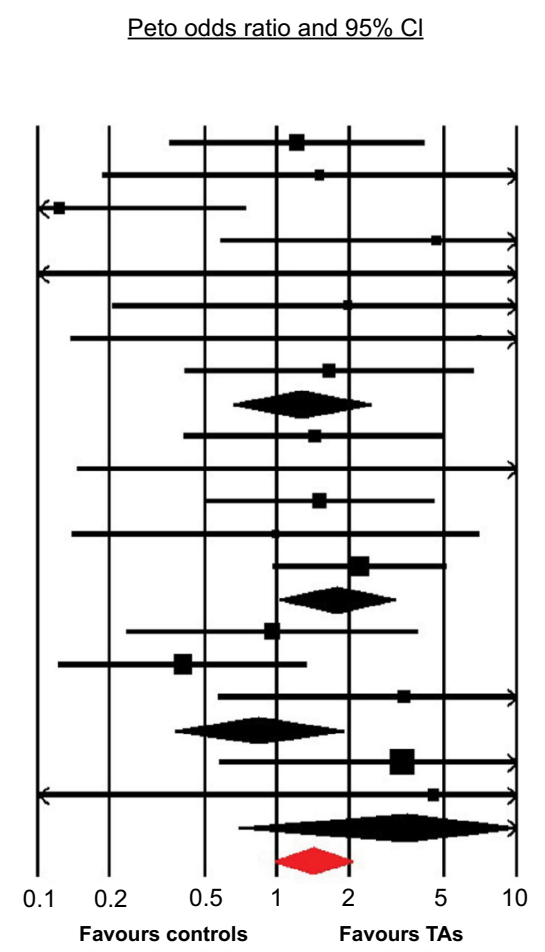

Figure 4 Subgroup analysis based on specific TAs for Peto odds ratio of complete response associated with TAs vs controls. Abbreviations: Als, angiogenesis inhibitors, EGFR, epidermal growth factor receptor; TAs, targeted agents. 


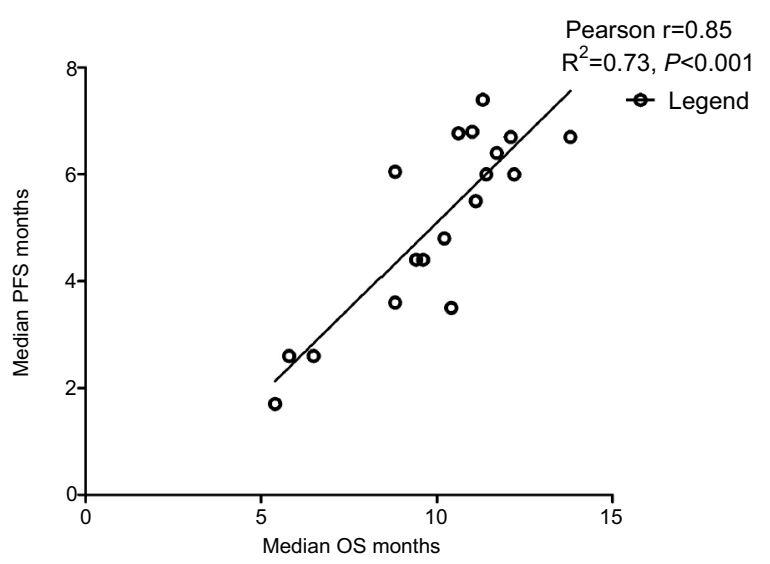

Figure 5 Correlation between median OS and PFS in gastroesophageal cancer patients received targeted agents.

Abbreviations: OS, overall survival; PFS, progression-free survival.

OR $1.41 ; 95 \%$ CI, 0.94-2.11; $P=0.06)$, but not for secondline therapy (Peto OR 1.47; 95\% CI, 0.60-3.55; $P=0.40$ ). In addition, subgroup analysis to specific TAs showed that the addition of anti-EGFR agents to chemotherapy in GEC significantly improved the $\mathrm{CR}$ rate in comparison with control (Peto OR 1.77; 95\% CI, 1.02-3.09; $P=0.044$ ), but not for other molecular TAs ( $P=0.49$ for angiogenesis inhibitors; $P=0.66$ for MET inhibitors). For patients with GEC, a common question is whether the patient needs chemotherapy plus TAs in first-line treatment. It is always difficult to make a decision because of the unclear survival benefit, potential toxicities, and high cost. The present study results supported the addition of anti-EGFR agents to first-line chemotherapy as initial treatment for unresectable metastatic GEC in order to pave the way for potentially radical surgery of the primary and metastatic sites. In addition, using the most active and well-tolerated therapy could provide a reduction of neoplastic mass and, as a consequence, result in the need for less aggressive surgery.

We also investigated the potential surrogate points for OS in GEC patients receiving TAs. We found that there is strong correlation between OS and PFS $(r=0.85)$, and this correlation is statistically significant $(P<0.001$; Figure 5$)$. In addition, a statistically significant correlation between ORR/ DCR and OS is observed $(r=0.86, P<0.001 ; r=0.82, P<0.001$, respectively), while no marked correlation is found between OS and CR ( $r=0.43, P=0.18$ ). Based on our findings, both PFS/ORR/DCR appears to be good surrogate endpoints for OS in GEC patients receiving TAs, although OS remains the historical and primary endpoint for studies in advanced GEC patients, and CR could not be a surrogate endpoint for OS.

The results of our meta-analysis represent the largest amount of evidence that adding TAs, especially anti-EGFR agents, is effective in increasing the rate of CR in GEC when compared with controls. The quality of this evidence is based on the high rate of the mean Jadad score for the included studies. Nevertheless, several limitations need to be mentioned. First of all, this meta-analysis only considers published literature, and lack of individual patient data prevents us from adjusting the treatment effect according to disease and patient variables. Second, we include GEC patients who received different TAs due to the limited sample size of patients treated with any single TAs, which would increase the clinical heterogeneity among included trials. Third, CR events are prospectively collected for each clinical trial, but our study is retrospective, and there are potentially important differences among the studies, which could be another source of heterogeneity. However, the pooled analysis indicates that there is no significant heterogeneity among the included trials. Finally, due to different types of treatment modalities investigated (oral vs intravenous), some of the included trials are open-label, with an inherent risk of bias. Although the literature search is comprehensive, the possibility of relevant publications remains might not be identified.

\section{Conclusion}

Although the CR is a rate event in advanced GEC patients, adding the TAs to therapies, especially for anti-EGFR agents, increases the chance of archiving CR in comparison with the controls. Further studies are still needed to investigate whether treatment with TAs can be discontinued in these patients. In addition, PFS, ORR, and DCR are significantly correlated with OS and could be used as surrogate endpoints in patients with GEC who received TA therapy, but not for CR.

\section{Ethics approval and consent to participate}

This meta-analysis was approved by the institutional review board; the need for informed patient consent for inclusion was waived.

\section{Availability of data and material}

All data generated or analyzed during this study are included in this published article.

\section{Acknowledgments}

We would like to thank the reviewers whose comments and suggestions greatly improved this manuscript. We also like to thank the sponsorship of the National Key R\&D Program of China (No. 2017YFC0907104). 


\section{Author contributions}

All authors contributed to data analysis, drafting and revising the article, gave final approval of the version to be published, and agree to be accountable for all aspects of the work.

\section{Disclosure}

The authors report no conflicts of interest in this work.

\section{References}

1. Jemal A, Bray F, Center MM, Ferlay J, Ward E, Forman D. Global cancer statistics. CA Cancer J Clin. 2011;61(2):69-90.

2. Ferlay J, Soerjomataram I, Dikshit R, et al. Cancer incidence and mortality worldwide: sources, methods and major patterns in GLOBOCAN 2012. Int J Cancer. 2015;136(5):E359-E386.

3. Davidson M, Okines AF, Starling N. Current and future therapies for advanced gastric cancer. Clin Colorectal Cancer. 2015;14(4):239-250.

4. Kim HS, Kim HJ, Kim SY, et al. Second-line chemotherapy versus supportive cancer treatment in advanced gastric cancer: a meta-analysis. Ann Oncol. 2013;24(11):2850-2854.

5. Janowitz T, Thuss-Patience P, Marshall A, et al. Chemotherapy vs supportive care alone for relapsed gastric, gastroesophageal junction, and oesophageal adenocarcinoma: a meta-analysis of patient-level data. $\mathrm{Br}$ J Cancer. 2016;114(4):381-387.

6. Shah MA. Update on metastatic gastric and esophageal cancers. J Clin Oncol. 2015;33(16):1760-1769.

7. Waddell T, Verheij M, Allum W, Cunningham D, Cervantes A, Arnold D. Gastric cancer: ESMO-ESSO-ESTRO clinical practice guidelines for diagnosis, treatment and follow-up. Eur J Surg Oncol. 2014;40(5):584-591.

8. Price TJ, Shapiro JD, Segelov E, et al. Management of advanced gastric cancer. Expert Rev Gastroenterol Hepatol. 2012;6(2):199-209.

9. Tomasello G, Ghidini M, Liguigli W, Ratti M, Toppo L, Passalacqua R. Targeted therapies in gastric cancer treatment: where we are and where we are going. Invest New Drugs. 2016;34(3):378-393.

10. Yazici O, Sendur MA, Ozdemir N, Aksoy S. Targeted therapies in gastric cancer and future perspectives. World J Gastroenterol. 2016;22(2):471-489.

11. Wang CW, Fang XH. The role of targeted agents in the treatment of advanced gastric cancer: a meta-analysis of randomized controlled trials. Eur Rev Med Pharmacol Sci. 2016;20(9):1725-1732.

12. Ciliberto D, Staropoli N, Caglioti F, et al. A systematic review and meta-analysis of randomized trials on the role of targeted therapy in the management of advanced gastric cancer: Evidence does not translate? Cancer Biol Ther. 2015;16(8):1148-1159.

13. Zhao TT, Xu H, Xu HM, et al. The efficacy and safety of targeted therapy with or without chemotherapy in advanced gastric cancer treatment: a network meta-analysis of well-designed randomized controlled trials. Gastric Cancer. 2018;21(3):361-371.

14. Janmaat VT, Steyerberg EW, van der Gaast A, et al. Palliative chemotherapy and targeted therapies for esophageal and gastroesophageal junction cancer. Cochrane Database Syst Rev. 2017;11:CD004063.

15. Moher D, Liberati A, Tetzlaff J, Altman DG; PRISMA Group. Preferred reporting items for systematic reviews and meta-analyses: the PRISMA statement. PLoS Med. 2009;6(7):e1000097.

16. Moher D, Cook DJ, Eastwood S, Olkin I, Rennie D, Stroup DF. Improving the quality of reports of meta-analyses of randomised controlled trials: the QUOROM statement. Quality of Reporting of Meta-analyses. Lancet. 1999;354(9193):1896-1900.

17. Cheyne WW. An Address ON ACUTE ABDOMINAL SYMPTOMS: Delivered before the Walthamstow Division of the Metropolitan Counties Branch of the British Medical Association. Br Med J. 1905;1(2320):1313-1316.
18. Zintzaras E, Ioannidis JP. Heterogeneity testing in meta-analysis of genome searches. Genet Epidemiol. 2005;28(2):123-137.

19. Dersimonian R, Laird N. Meta-analysis in clinical trials. Control Clin Trials. 1986;7(3):177-188.

20. Begg CB, Mazumdar M. Operating characteristics of a rank correlation test for publication bias. Biometrics. 1994;50(4):1088-1101.

21. Egger M, Davey Smith G, Schneider M, Minder C. Bias in meta-analysis detected by a simple, graphical test. BMJ. 1997;315(7109):629-634.

22. Jadad AR, Moore RA, Carroll D, et al. Assessing the quality of reports of randomized clinical trials: is blinding necessary? Control Clin Trials. 1996;17(1):1-12.

23. Bang YJ, van Cutsem E, Feyereislova A, et al. Trastuzumab in combination with chemotherapy versus chemotherapy alone for treatment of HER2-positive advanced gastric or gastro-oesophageal junction cancer (ToGA): a phase 3, open-label, randomised controlled trial. Lancet. 2010;376(9742):687-697.

24. Ohtsu A, Shah MA, van Cutsem E, et al. Bevacizumab in combination with chemotherapy as first-line therapy in advanced gastric cancer: a randomized, double-blind, placebo-controlled phase III study. J Clin Oncol. 2011;29(30):3968-3976.

25. Lordick F, Kang YK, Chung HC, et al. Capecitabine and cisplatin with or without cetuximab for patients with previously untreated advanced gastric cancer (EXPAND): a randomised, open-label phase 3 trial. Lancet Oncol. 2013;14(6):490-499.

26. Ohtsu A, Ajani JA, Bai YX, et al. Everolimus for previously treated advanced gastric cancer: results of the randomized, double-blind, phase III GRANITE-1 study. J Clin Oncol. 2013;31(31):3935-3943.

27. Waddell T, Chau I, Cunningham D, et al. Epirubicin, oxaliplatin, and capecitabine with or without panitumumab for patients with previously untreated advanced oesophagogastric cancer (REAL3): a randomised, open-label phase 3 trial. Lancet Oncol. 2013;14(6):481-489.

28. Fuchs CS, Tomasek J, Yong CJ, et al. Ramucirumab monotherapy for previously treated advanced gastric or gastro-oesophageal junction adenocarcinoma (REGARD): an international, randomised, multicentre, placebo-controlled, phase 3 trial. Lancet. 2014;383(9911):31-39.

29. Shen L, Li J, Xu J, et al. Bevacizumab plus capecitabine and cisplatin in Chinese patients with inoperable locally advanced or metastatic gastric or gastroesophageal junction cancer: randomized, double-blind, phase III study (AVATAR study). Gastric Cancer. 2015;18(1):168-176.

30. Wilke H, Muro K, van Cutsem E, et al. Ramucirumab plus paclitaxel versus placebo plus paclitaxel in patients with previously treated advanced gastric or gastro-oesophageal junction adenocarcinoma (RAINBOW): a doubleblind, randomised phase 3 trial. Lancet Oncol. 2014;15(11):1224-1235.

31. Du F, Zheng Z, Shi S, et al. S-1 and cisplatin with or without nimotuzumab for patients with untreated unresectable or metastatic gastric cancer: a randomized, open-label phase 2 trial. Medicine. 2015;94(23):e958.

32. Shah MA, Bang YJ, Lordick F, et al. Effect of fluorouracil, leucovorin, and oxaliplatin with or without onartuzumab in HER2-negative, METpositive gastroesophageal adenocarcinoma: the METGastric randomized clinical trial. JAMA Oncol. 2017;3(5):620-627.

33. Catenacci DVT, Tebbutt NC, Davidenko I, et al. Rilotumumab plus epirubicin, cisplatin, and capecitabine as first-line therapy in advanced MET-positive gastric or gastro-oesophageal junction cancer (RILOMET-1): a randomised, double-blind, placebo-controlled, phase 3 trial. Lancet Oncol. 2017;18(11):1467-1482.

34. Bang YJ, Xu RH, Chin K, et al. Olaparib in combination with paclitaxel in patients with advanced gastric cancer who have progressed following first-line therapy (GOLD): a double-blind, randomised, placebocontrolled, phase 3 trial. Lancet Oncol. 2017;18(12):1637-1651.

35. Yoon HH, Bendell JC, Braiteh FS, et al. Ramucirumab combined with FOLFOX as front-line therapy for advanced esophageal, gastroesophageal junction, or gastric adenocarcinoma: a randomized, double-blind, multicenter Phase II trial. Ann Oncol. 2016;27(12):2196-2203.

36. Shah MA, Cho JY, Tan IB, et al. A randomized phase II study of FOLFOX with or without the MET inhibitor onartuzumab in advanced adenocarcinoma of the stomach and gastroesophageal junction. Oncologist. 2016;21(9):1085-1090. 
37. Pavlakis N, Sjoquist KM, Martin AJ, et al. Regorafenib for the treatment of advanced gastric cancer (INTEGRATE): a multinational placebocontrolled phase II trial. J Clin Oncol. 2016;34(23):2728-2735.

38. Moehler M, Gepfner-Tuma I, Maderer A, et al. Sunitinib added to FOLFIRI versus FOLFIRI in patients with chemorefractory advanced adenocarcinoma of the stomach or lower esophagus: a randomized, placebo-controlled phase II AIO trial with serum biomarker program. BMC Cancer. 2016;16:699.

39. Li J, Qin S, Xu J, et al. Randomized, double-blind, placebo-controlled phase III trial of apatinib in patients with chemotherapy-refractory advanced or metastatic adenocarcinoma of the stomach or gastroesophageal junction. J Clin Oncol. 2016;34(13):1448-1454.

40. Hecht JR, Bang YJ, Qin SK, et al. Lapatinib in combination with capecitabine plus oxaliplatin in human epidermal growth factor receptor 2-positive advanced or metastatic gastric, esophageal, or gastroesophageal adenocarcinoma: TRIO-013/LOGiC - a randomized phase III trial. J Clin Oncol. 2016;34(5):443-451.

41. Teker F, Canbaz F, Kemal Y, Yucel I. A case of gastric cancer with liver metastases had a complete response with cisplatin and capecitabine as third-line chemotherapy. J Cancer Res Ther. 2015;11(4):1026.
42. Toyokawa T, Ohira M, Sakurai K, et al. Long-term survival with complete remission after hepatic arterial infusion chemotherapy for liver metastasis from gastric cancer: a case report. World J Surg Oncol. 2015;13:268.

43. Izuishi K, Kobayashi M, Sano T, Mori H, Ebara K. Pathological complete response and long-term survival in a very elderly patient after neoadjuvant chemotherapy for locally advanced, unresectable gastric cancer. Case Rep Oncol Med. 2014;2014:532924-532925.

44. Gallagher DJ, Kemeny N. Metastatic colorectal cancer: from improved survival to potential cure. Oncology. 2010;78(3-4):237-248.

45. Kurian S, Qazilbash M, Fay J, et al. Complete response after high-dose chemotherapy and autologous hematopoietic stem cell transplantation in metastatic breast cancer results in survival benefit. Breast J. 2006;12(6): 531-535.

46. Kantarjian HM, Cortes JE, O'Brien S, et al. Long-term survival benefit and improved complete cytogenetic and molecular response rates with imatinib mesylate in Philadelphia chromosome-positive chronic-phase chronic myeloid leukemia after failure of interferon-alpha. Blood. 2004;104(7):1979-1988. 


\section{Supplementary materials}

Funnel plot of standard error by log peto odds ratio

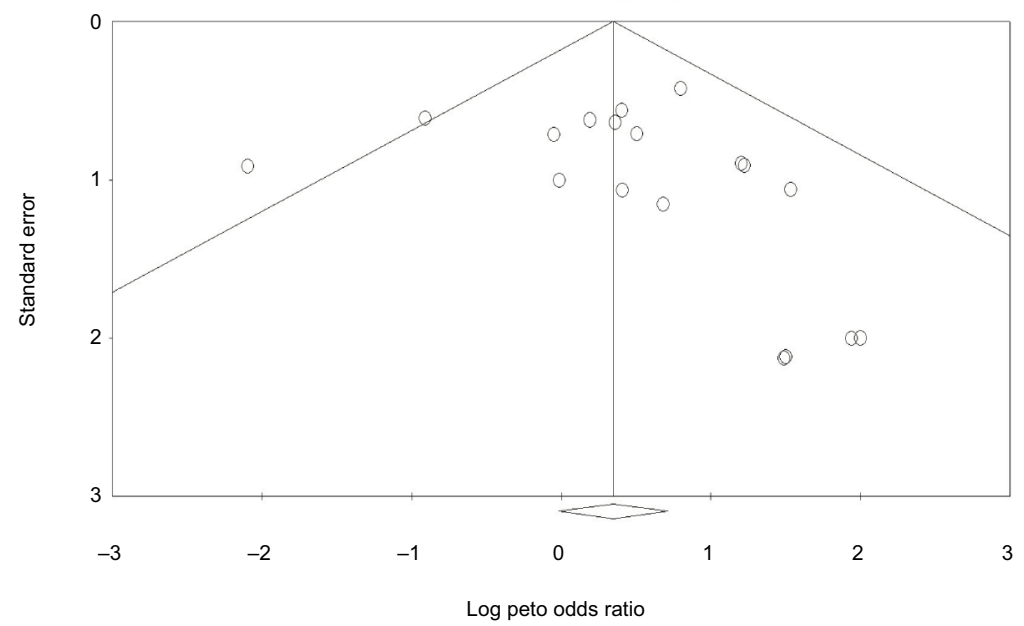

Figure SI Publication bias of Peto odds ratio associated with targeted agents.

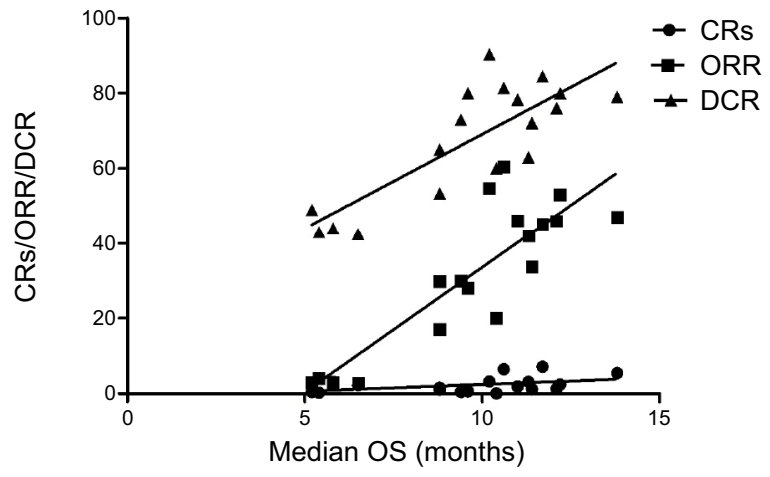

Figure S2 Correlation between median OS and ORR/DCR/CR in gastroesophageal cancer patients received targeted agents.

Abbreviations: CR, complete response; DCR, disease control rate; ORR, objective response rate; OS, overall survival.

\section{Publish your work in this journal}

Cancer Management and Research is an international, peer-reviewed open access journal focusing on cancer research and the optimal use of preventative and integrated treatment interventions to achieve improved outcomes, enhanced survival and quality of life for the cancer patient. The manuscript management system is completely online and includes a very quick and fair peer-review system, which is all easy to use. Visit $\mathrm{http}: / / \mathrm{www}$.dovepress.com/testimonials.php to read real quotes from published authors. 